\title{
THE LIPID COMPOSITION OF SERUM IN PATIENTS WITH LIVER DISEASE *
}

\author{
BY GERALD B. PHILLIPS
}

\begin{abstract}
(From the Departments of Biochemistry and Medicine, College of Physicians and Surgeons, Columbia University, and Presbyterian Hospital, New York, N. Y.)
\end{abstract}

(Submitted for publication February 8, 1960 ; accepted July 15, 1960)

The association of a serum lipid abnormality and liver disease has been known since 1862, when Flint (1) described the accumulation of "cholesterine" in the blood of patients with liver disease as the result of decreased excretion of this substance into the bile. Subsequent observations disclosed that this increase in serum cholesterol concentration was largely in the unesterified (free) fraction, so that the ratio of free/total cholesterol was elevated (2-4). Man, Kartin, Durlacher and Peters (5), in 1945, showed that the lipid phosphorus concentration and the ratio of lipid phosphorus/cholesterol were also elevated in certain patients with liver disease. The elevation in serum lipid phosphorus concentration appeared to be attributable largely to an increase in the serum lecithin concentration (6-9). The hyperlipemia and the increase in the ratio of free/total cholesterol, moreover, showed some correlation with the degree of jaundice, whether due to biliary obstruction or to parenchymal damage $(5,10-12)$.

Abnormalities in the serum lipoprotein composition have also been described in patients with liver disease and jaundice. Marked increases in the $\mathrm{S}_{\mathrm{f}} 6$ and $\mathrm{S}_{\mathrm{f}} 8$ with varying increases in the $\mathrm{S}_{\mathrm{f}} 10-17$ ultracentrifugal classes of lipoproteins have been reported in patients with biliary cirrhosis (13). In patients with hepatitis, increases in the $\mathrm{S}_{\mathrm{f}} 0-12,12-20$, and $20-100$ classes, which correlated positively with the icteric index, and decreases in the $S_{\mathrm{f}} 100-400$ class, which correlated negatively with the icteric index, have been found (14). Increased concentrations of $\beta$-lipoprotein and decreased-to-absent concentrations of $\alpha$-lipoprotein have been observed with zone electrophoresis of serum from patients with jaundice (15). Similar findings have been reported with

* This investigation was supported in part by a research grant (H-2907) from the National Heart Institute, Bethesda, Md., and in part by a research grant from the American Heart Association. filter paper electrophoresis $(16,17)$ and ultracentrifugation (17-19). Abnormalities in these lipoprotein fractions, moreover, have been demonstrated by both chemical $(15,17,19)$ and immunological means (20). By ultracentrifugal analysis, Havel, Eder and Bragdon (19) demonstrated a decreased ratio of cholesterol/phospholipid in the fractions with density (D) $<1.019$, $1.019-1.063$, and $>1.063$ as well as an increase in the concentration of the fraction $\mathrm{D}<1.063$ and a decrease in the concentration of the fraction $\mathrm{D}>$ 1.063 .

In the present investigation, a chromatographic technique for the estimation of the main individual phospholipids of serum $(21,22)$ was employed in order to characterize further the serum lipid abnormalities of patients with liver disease. The lipids were analyzed in this way in the whole serum of 12 patients with parenchymatous or obstructive jaundice, 3 patients with cirrhosis without jaundice, and 3 patients with bile fistula. In 10 of these patients, in addition, the lipids of the ultracentrifugally separated serum fractions $\mathrm{D}<$ $1.019,<1.063$, and $>1.063$ were analyzed in the same manner.

\section{MATERIALS AND METHODS}

Six male and 12 female patients on the wards of the Presbyterian Hospital were studied. A brief description follows.

M.N., D.C., N.W. and P.K. were females with jaundice of 8 to 16 years' duration, and hepatosplenomegaly. Laboratory studies of the serum showed negative cephalin flocculation reactions and elevated alkaline phosphatase concentrations in all and a low albumin concentration in 3 of the 4 patients tested; these were classified as having primary biliary cirrhosis. Patient M.N., in addition, had diabetes mellitus known for 3 years. At the time of the serum lipid analysis, M.N. was receiving bile salts orally and P.K. had been on prednisone, $10 \mathrm{mg}$ per day for 1 week.

Patient L.U. had jaundice of 8 years' duration secondary to postoperative bile duct stricture. Patient K.M. 
had jaundice of the obstructive type with a negative cephalin flocculation reaction and an elevated serum alkaline phosphatase concentration. The jaundice, which started about 11 days before the serum lipid analysis, rapidly decreased during the week before the serum lipid analysis, and it was felt that this spontaneously reversible jaundice was due either to passage of a common duct stone, as stabbing right upper quadrant pain was present, or to the ingestion of chlorpromazine, which was stopped about 10 days prior to the onset of jaundice.

Patient I.H. was in hepatic coma, at the time of the serum lipid analysis, as a result of the acute hepatic insufficiency of the chronic alcoholic (23) and died two days later. His liver and spleen were not palpable and the cephalin flocculation reaction was $3+$. He had received a total of $40 \mathrm{mg}$ of prednisone during the 2 days prior to the serum lipid analysis.

Patients J.E., G.L., M.C., E.E. and J.M. had had typical acute viral hepatitis with jaundice for 1 to 4 weeks before the serum lipid analysis. All had hepatomegaly except J.E., in whom the liver was not felt, and all had $3+$ or $4+$ cephalin flocculation reactions except J.E., who had a negative cephalin flocculation reaction but a $2+$ thymol turbidity reaction. Only E.E. had a low serum albumin concentration, which was about 40 per cent of the normal.

Patients M.M., E.H. and J.C. had cirrhosis apparently on the basis of chronic alcoholism. All had firm enlarged livers and M.M. and E.H. had ascites and edema. The cephalin flocculation reaction was $2+$ in M.M., $3+$ in E.H., and negative in J.C. J.C. had 20 per cent retention of sulfobromophthalein at 30 minutes after administration.

Patients H.S. and F.M. were draining bile through common bile duct $\mathrm{T}$-tubes following common bile duct exploration for choledocholithiasis. At the time of the lipid analysis, H.S. had drained about $275 \mathrm{ml}$ of bile per day for 10 days and F.M. about $450 \mathrm{ml}$ of bile per day for 8 days. L.K. had had a cholecystostomy which was performed for acute cholecystitis; because of a postoperative myocardial infarction, further surgery was delayed. At the time of the lipid analysis, which was done about 6 months after the cholecystostomy was performed, L.K. was draining about $150 \mathrm{ml}$ of bile per day.

The direct serum bilirubin concentrations were measured in the hospital routine laboratory by the method of Malloy and Evelyn (24) and are reported in Table I. The values reported were obtained within 1 to 2 days of the serum lipid analyses except in Patients M.N. (11 days before), D.C. ( 5 days before), E.H. ( 8 days before) and L.K. (4 days before).

All of the serum samples were obtained from fasting patients. A lipid extract of each serum sample was prepared within 6 hours after withdrawal and stored in vacuo at $-30^{\circ} \mathrm{C}$ for as long as several weeks. The lipid extract was then chromatographed in duplicate on silicic acid, using chloroform-methanol-water mixtures for elution, in order to separate and quantitate the individual phospholipids, cholesterol, cholesterol ester, and triglycer- ide. In 10 patients, aliquots of the serum samples were also adjusted as to density and ultracentrifuged in order to separate the fractions $\mathrm{D}<1.019,<1.063$, and $>1.063$. In L.U. the 3 fractions separated were $D<1.019,1.019$ 1.063 , and $>1.063$. All of the ultracentrifugally separated fractions were then extracted and chromatographed in the same manner as the whole serum samples. The methods used for extraction, chromatography and ultracentrifugation have been described previously $(21,22,25)$. The column fractions were analyzed for phosphorus by the method of Fiske and Subbarow (26), for cholesterol and cholesterol ester by the method of Schoenheimer and Sperry (27) as modified by Sperry and Webb (28), and for ester bonds by the method of Rapport and Alonzo (29). Serum triglyceride concentration was calculated by subtracting the serum cholesterol ester concentration from the total serum nonphosphorus-containing lipid ester concentration and dividing by 3 .

The normal values used in Table I for whole serum lipids include a combined series of 7 previously reported (22) and of 8 previously not reported; the values for the ultracentrifugally separated serum fractions of this latter group, however, have been reported (25) except for cholesterol, cholesterol ester and triglyceride, and are the normal values quoted in Tables II to VII. These 15 normal values were obtained from 10 male and 5 female subjects with an average age of $32 \pm 11$ (SD) years.

The estimation of lysolecithin by the column chromatographic method used is not precise, one reason being that lysolecithin comprises only about 7 to 8 per cent of the total phospholipid of normal human serum; a more important reason, however, is that the lysolecithin fraction, which is the final phosphorus-containing fraction eluted from the column, is contaminated with lecithin and sphingomyelin. In a previous communication (21), it was shown that this final fraction obtained on chromatography of normal whole serum lipid extract was composed predominantly of lysolecithin, but contained about 10 per cent lecithin and 10 per cent sphingomyelin. In calculating this final fraction, therefore, 80 per cent was considered to be lysolecithin, and 10 per cent was added to the lecithin and 10 per cent to the sphingomyelin fraction (22). On chromatographing samples of lecithin and sphingomyelin containing no lysolecithin, however, these substances were found in the final phosphorus-containing fraction, and it appeared that the amount of lecithin and sphingomyelin in this final fraction was related to the total amount of material in the lecithin and sphingomyelin fractions, respectively, of the lipid extract; thus, by subtracting from this final fraction the appropriate percentage of the lecithin and sphingomyelin fractions, a more accurate approximation of the lysolecithin concentration should be obtained. To determine the respective percentages of the lecithin and sphingomyelin fractions appearing in the final fraction, 5 lipid extracts of normal human serum were chromatographed in amounts ranging from 10 to $18 \mu$ moles of lipid phosphorus per $\mathrm{g}$ of silicic acid. When the final fraction of each was analyzed by 
rechromatography, an average of 1.3 (range 0.9 to 1.6) per cent of the lecithin fraction and 4.9 (range 2.3 to 7.9 ) per cent of the sphingomyelin fraction appeared in the final fraction, these values showing no correlation with the amount of lipid phosphorus chromatographed per gram of silicic acid. Using these figures, therefore, all of the normal values recorded here were recalculated from the reported data so that 1.3 per cent of the lecithin fraction and 4.9 per cent of the sphingomyelin fraction were considered to be in the final fraction. Thus, these amounts were subtracted from the lysolecithin fraction and added, respectively, to the lecithin and sphingomyelin fractions, the rest of the final fraction being considered as lysolecithin. The reported values for the fraction with density $>1.063$ (25) had already been calculated in this way. The values for the patients in the present series were calculated in the same way. When 3 samples of normal serum lecithin were chromatographed in amounts of 3.5, 7.5 and $11.3 \mu$ moles lipid phosphorus per $\mathrm{g}$ of silicic acid, 1.8, 1.2 and 1.4 per cent of the total lecithin, respectively, appeared in the final fraction. Two samples of whole human red blood cell lipid extract, which contained about one-half the relative lecithin concentration as human serum, when chromatographed in the same way, showed 1.0 to 1.1 per cent of the lecithin fraction in the final fraction. The markedly decreased concentrations of lysolecithin reported in the present study, which were reflected by a decrease in the concentrations of the uncorrected lysolecithin fraction, therefore, do not appear to be related to the associated high concentration of lecithin found. Confirmatory evidence for the decreased lysolecithin concentration was obtained, moreover, by estimating the size of the spots obtained by chromatography of the lipid extract on silicic acid-impregnated paper.

The concentrations of the individual phospholipids in the density fractions were calculated on the basis of the actual amounts of phosphorus eluted from the column. The corresponding normal values reported previously (25) were calculated on the basis of 100 per cent recovery from the column. Since the average recovery was less than 100 per cent, these normal values were recalculated on the basis of the actual amounts of phosphorus eluted from the column, and appear in Tables III-V.

\section{RESULTS}

\section{Whole serum}

The values for the concentrations of the various lipids measured in the whole serum of all of the patients studied are presented in Table I. These patients can be divided into three groups : 1) patients with jaundice (the top 12 in Table I) with direct serum bilirubin concentration greater than $1.8 \mathrm{mg}$ per $100 \mathrm{ml}, 2$ ) patients with cirrhosis with direct serum bilirubin concentration less than 1.8 $\mathrm{mg}$ per $100 \mathrm{ml}$, and 3) patients with bile fistula.

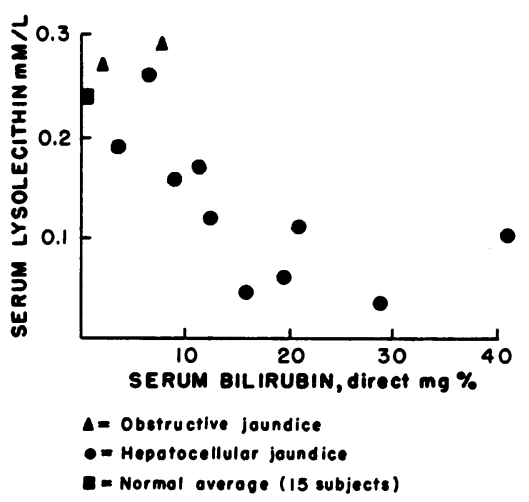

Fig. 1. The Relationship OF SERUM LYSOLECITHIN CONCENTRATION TO DIRECT SERUM BILIRUBIN CONCENTRATION IN PATIENTS WITH JAUNDICE.

Patients with jaundice. In these 12 patients, the total lipid phosphorus concentration varied over a wide range. The lecithin concentration was elevated $^{1}$ in 8 of the 12 patients and correlated well with the total lipid phosphorus concentration, as it comprised about three-fourths of the latter. The sphingomyelin and "cephalin" concentrations appeared to correlate, but less well, with the total lipid phosphorus concentration. The sphingomyelin concentration tended to be normal but was elevated in the three patients with the highest total lipid phosphorus concentrations, and the "cephalin" concentration was elevated. The lysolecithin concentration was lowered in all patients with a direct serum bilirubin concentration greater than 11.4 $\mathrm{mg}$ per $100 \mathrm{ml}$, and an inverse correlation between the concentrations of serum lysolecithin and direct serum bilirubin is suggested in Figure 1. The two patients with the obstructive type of jaundice, whose direct serum bilirubin concentrations were 7.6 and $1.8 \mathrm{mg}$ per $100 \mathrm{ml}$, respectively, had normal lysolecithin concentrations. The lowest lysolecithin concentration was seen in the patient (I.H.) with acute hepatic insufficiency and coma.

The relative amounts of lecithin and sphingomyelin showed more consistent changes than did the absolute amounts. The percentage of the total phospholipid analyzed as lecithin was elevated in 11 and the sphingomyelin/lecithin ratio was decreased in all of the patients (Figure 2). The

1 A value designated as elevated or lowered means that it is beyond twice the standard deviation from the average. 


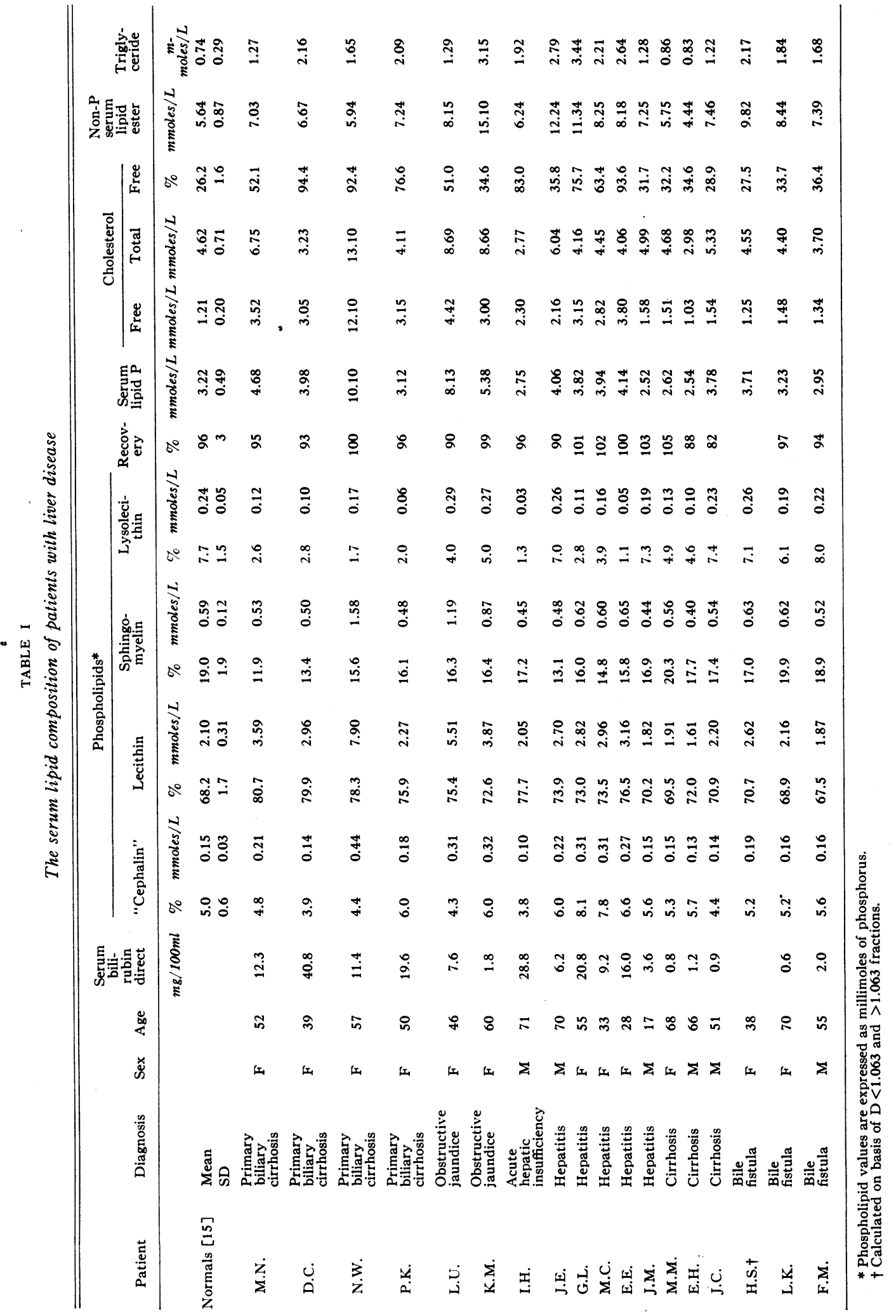




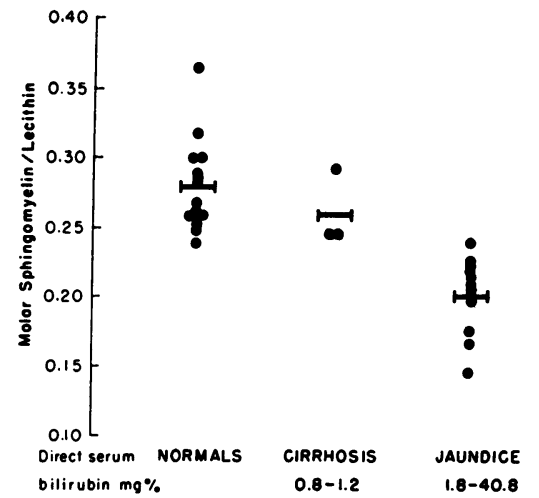

Fig. 2. The MOLAR SPHINGOMYelin/LECITHin RATIOS OF SERUM.

percentage of the total phospholipid analyzed as "cephalin" tended to be elevated in the patients with hepatitis.

The free cholesterol concentration as well as the ratio of free/total cholesterol was elevated in all of these patients but one, while the total cholesterol concentration varied considerably. The cholesterol ester concentration, like the lysolecithin concentration, appeared to be inversely related to the direct serum bilirubin concentration, as is seen in Figure 3.

The serum triglyceride concentration was elevated in nine of the patients. All of the sera were

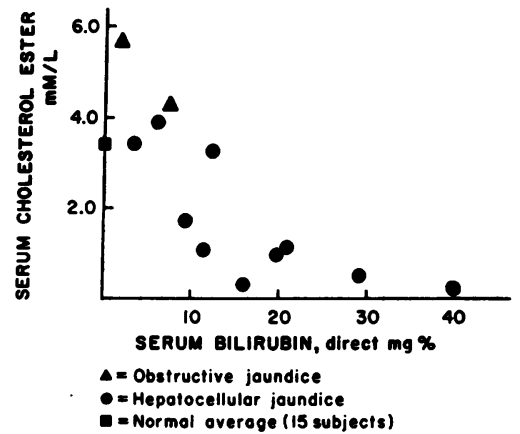

Fig. 3. The Relationship OF SERUM Cholesterol ESTER CONCENTRATION TO DIRECT SERUM BILIRUBIN CONCENTRATION IN PATIENTS WITH JAUNDICE.

clear on inspection except that of Patient J.M., whose serum showed a faint opalescence.

Patients with cirrhosis. The three patients with cirrhosis did not show the lipid changes seen in the patients with jaundice, except for some elevation of the ratio of free/total cholesterol in two, lowering of the cholesterol ester concentration in one, and lowering of the concentration of lysolecithin in two. The latter two patients had ascites and edema. All of the sera were clear on inspection.

Patients with bile fistula. The three patients with bile fistula likewise did not show the changes seen in the patients with jaundice except for an

TABLE II

Distribution of serum lipid phosphorus in density fractions

\begin{tabular}{|c|c|c|c|c|c|c|c|c|c|}
\hline \multirow[t]{2}{*}{ Patient } & \multirow[t]{2}{*}{ Diagnosis } & \multicolumn{2}{|c|}{$\mathrm{D}<1.019$} & \multicolumn{2}{|c|}{$\mathrm{D}<1.063$} & \multicolumn{2}{|c|}{$\mathrm{D}>1.063$} & \multirow{2}{*}{$\frac{\text { Recovery* }}{\%}$} & \multirow{2}{*}{$\begin{array}{c}\begin{array}{c}\text { Total } \\
\text { serum } \\
\text { lipid P }\end{array} \\
\text { mmoles } / L\end{array}$} \\
\hline & & mmoles $/ L$ & $\%$ total & mmoles $/ L$ & $\%$ total & mmoles $/ L$ & $\%$ total & & \\
\hline Normals & Average & 0.49 & 18.0 & 1.37 & 45 & 1.65 & 55 & 94 & 3.21 \\
\hline [8] & SD & 0.29 & 10.6 & 0.35 & 6 & 0.27 & 6 & 5 & 0.62 \\
\hline N.W. & $\begin{array}{l}\text { Primary biliary } \\
\text { cirrhosis }\end{array}$ & 0.28 & 2.8 & 9.70 & 96 & 0.42 & 4 & 100 & 10.1 \\
\hline L.U. & Obstructive & 0.67 & 10.0 & $5.18 \dagger$ & $77 \dagger$ & 1.55 & 23 & 87 & 7.72 \\
\hline K.M. & Obstructive & 0.98 & 20.1 & 3.90 & 80 & 0.97 & 20 & 91 & 5.38 \\
\hline I.H. & $\begin{array}{l}\text { Acute hepatic } \\
\text { insufficiency }\end{array}$ & $\ddagger$ & $\ddagger$ & 2.22 & 90 & 0.24 & 10 & 90 & 2.75 \\
\hline J.E. & Hepatitis & 0.67 & 15.9 & 2.98 & 71 & 1.23 & 29 & 104 & 4.06 \\
\hline M.M. & Cirrhosis & 0.49 & 18.5 & 1.11 & 42 & 1.51 & 58 & 100 & 2.62 \\
\hline E.H. & Cirrhosis & 0.54 & 21.6 & 1.23 & 49 & 1.27 & 51 & 98 & 2.54 \\
\hline J.C. & Cirrhosis & 0.30 & 9.3 & 1.67 & 53 & 1.50 & 47 & 84 & 3.78 \\
\hline H.S. & Bile fistula & 1.10 & 30.7 & 2.04 & 57 & 1.54 & 43 & 96 & 3.71 \\
\hline L.K. & Bile fistula & 0.64 & 18.9 & 1.82 & 54 & 1.57 & 46 & 105 & 3.23 \\
\hline
\end{tabular}

* Per cent recovery of total serum lipid $\mathrm{P}$ from 1.063 density tube after centrifugation. † Calculated by adding D $<1.019$ and D1.019-1.063 fractions.

† Sample lost. ' 
TABLE III

Phospholipid composition of fraction with density $<1.019^{*}$

\begin{tabular}{|c|c|c|c|c|c|c|c|c|c|}
\hline Patient $\dagger$ & Diagnosis & \multicolumn{2}{|c|}{ “Cephalin" } & \multicolumn{2}{|c|}{ Lecithin } & \multicolumn{2}{|c|}{ Sphingomyelin } & \multicolumn{2}{|c|}{ Lysolecithin } \\
\hline Normals & Average & $\begin{array}{c}\text { mmoles } / L \\
0.032\end{array}$ & $\begin{array}{c}\% \text { total } \\
5.7\end{array}$ & $\begin{array}{c}\text { mmoles } / L \\
0.39\end{array}$ & $\begin{array}{c}\% \text { total } \\
66.4\end{array}$ & $\begin{array}{c}\text { mmoles } / L \\
0.15\end{array}$ & $\begin{array}{c}\% \text { total } \\
23.5\end{array}$ & $\begin{array}{c}\text { mmoles } / L \\
0.028\end{array}$ & $\begin{array}{c}\text { \% total } \\
4.5\end{array}$ \\
\hline L.U. & $\begin{array}{c}\text { Obstructive } \\
\text { jaundice }\end{array}$ & 0.034 & 5.4 & 0.46 & 73.0 & 0.12 & 18.7 & 0.018 & 2.9 \\
\hline K.M. & $\begin{array}{c}\text { Obstructive } \\
\text { jaundice }\end{array}$ & 0.061 & 6.5 & 0.67 & 72.0 & 0.18 & 19.0 & 0.023 & 2.5 \\
\hline $\begin{array}{l}\text { J.E. } \\
\text { L.K. }\end{array}$ & $\begin{array}{l}\text { Hepatitis } \\
\text { Bile fistula }\end{array}$ & $\begin{array}{l}0.049 \\
0.045\end{array}$ & $\begin{array}{l}6.8 \\
8.0\end{array}$ & $\begin{array}{l}0.51 \\
0.36\end{array}$ & $\begin{array}{l}70.4 \\
64.5\end{array}$ & $\begin{array}{l}0.14 \\
0.13\end{array}$ & $\begin{array}{l}19.0 \\
24.0\end{array}$ & $\begin{array}{l}0.028 \\
0.019\end{array}$ & $\begin{array}{l}3.9 \\
3.5\end{array}$ \\
\hline
\end{tabular}

* Phospholipid values are expressed as millimoles of phosphorus.

† Samples on other patients either not done or too inaccurate because of small quantity.

TABLE IV

Phospholipid composition of fraction with density $<1.063^{*}$

\begin{tabular}{|c|c|c|c|c|c|c|c|c|c|}
\hline \multirow[t]{2}{*}{ Patient } & \multirow[t]{2}{*}{ Diagnosis } & \multicolumn{2}{|c|}{ “Cephalin" } & \multicolumn{2}{|c|}{ Lecithin } & \multicolumn{2}{|c|}{ Sphingomyelin } & \multicolumn{2}{|c|}{ Lysolecithin } \\
\hline & & mmoles $/ L$ & $\%$ total & mmoles $/ L$ & $\%$ total & mmoles $/ L$ & $\%$ total & mmoles $/ L$ & $\%$ total \\
\hline Normals & Average & 0.053 & 4.4 & 0.87 & 66.6 & 0.34 & 26.0 & 0.039 & 3.0 \\
\hline & $\mathrm{SD}$ & 0.008 & 0.6 & 0.21 & 1.1 & 0.08 & 1.5 & 0.014 & 0.8 \\
\hline N.W. & $\begin{array}{l}\text { Primary biliary } \\
\text { cirrhosis }\end{array}$ & 0.427 & 4.4 & 7.60 & 78.3 & 1.51 & 15.6 & 0.165 & 1.7 \\
\hline L.U.† & $\begin{array}{l}\text { Obstructive } \\
\text { jaundice }\end{array}$ & 0.198 & 3.9 & 3.85 & 75.9 & 0.88 & 17.4 & 0.142 & 2.8 \\
\hline K. M. & $\begin{array}{l}\text { Obstructive } \\
\text { jaundice }\end{array}$ & 0.191 & 5.1 & 2.86 & 76.5 & 0.61 & 16.4 & 0.071 & 1.9 \\
\hline I.H. & $\begin{array}{l}\text { Acute hepatic } \\
\text { insufficiency }\end{array}$ & 0.072 & 3.5 & 1.64 & 79.6 & 0.33 & 16.0 & 0.017 & 0.8 \\
\hline J.E. & Hepatitis & 0.145 & 5.4 & 2.02 & 74.8 & 0.48 & 17.7 & 0.060 & 2.2 \\
\hline M.M. & Cirrhosis & 0.048 & 4.6 & 0.74 & 70.6 & 0.24 & 22.3 & 0.027 & 2.6 \\
\hline E.H. & Cirrhosis & 0.060 & 5.5 & 0.77 & 71.4 & 0.23 & 21.4 & 0.019 & 1.8 \\
\hline J.C. & Cirrhosis & 0.063 & 4.0 & 1.10 & 69.8 & 0.38 & 23.8 & 0.038 & 2.4 \\
\hline H.S. & Bile fistula & 0.102 & 5.1 & 1.39 & 69.6 & 0.44 & 21.9 & 0.066 & 3.3 \\
\hline L.K. & Bile fistula & $0.097 \ddagger$ & $5.6 \ddagger$ & 1.19 & 68.7 & 0.41 & 23.6 & 0.037 & 2.2 \\
\hline
\end{tabular}

* Phospholipid values are expressed as millimoles of phosphorus.

† Calculated by adding D $<1.019$ and D1.019-1.063 fractions.

$\ddagger$ Estimated.

TABLE $V$

Phospholipid composition of fraction with density $>1.063^{*}$

\begin{tabular}{|c|c|c|c|c|c|c|c|c|c|}
\hline \multirow[t]{2}{*}{ Patient $†$} & \multirow[t]{2}{*}{ Diagnosis } & \multicolumn{2}{|c|}{ “Cephalin" } & \multicolumn{2}{|c|}{ Lecithin } & \multicolumn{2}{|c|}{ Sphingomyelin } & \multicolumn{2}{|c|}{ Lysolecithin } \\
\hline & & mmoles $/ L$ & $\%$ total & mmoles $/ L$ & $\%$ total & mmoles $/ L$ & $\%$ total & mmoles $/ L$ & $\%$ total \\
\hline Normals & Average & 0.087 & 5.2 & 1.15 & 70.0 & 0.22 & 13.6 & 0.18 & 11.1 \\
\hline & SD & 0.025 & 0.7 & 0.22 & 2.1 & 0.05 & 1.3 & 0.03 & 2.8 \\
\hline L.Ü.' & $\begin{array}{c}\text { Obstructive } \\
\text { jaundice }\end{array}$ & 0.064 & 4.0 & 1.27 & 78.6 & 0.13 & 8.3 & 0.146 & 9.0 \\
\hline K.M. & $\begin{array}{l}\text { Obstructive } \\
\text { jaundice }\end{array}$ & 0.065 & 6.2 & 0.78 & 73.9 & 0.11 & 10.5 & 0.099 & 9.4 \\
\hline J.E. & Hepatitis & 0.073 & 6.9 & 0.69 & 65.1 & 0.11 & 10.5 & 0.185 & 17.5 \\
\hline M.M. & Cirrhosis & 0.079 & 5.5 & 1.02 & 71.2 & 0.24 & 16.6 & 0.098 & 6.8 \\
\hline E.H. & Cirrhosis & 0.076 & 6.6 & 0.82 & 71.7 & 0.18 & 15.8 & 0.068 & 6.0 \\
\hline J.C. & Cirrhosis & 0.065 & 5.3 & 0.86 & 70.5 & 0.15 & 11.9 & 0.150 & 12.3 \\
\hline H.S. & Bile fistula & 0.082 & 5.3 & 1.11 & 72.1 & 0.16 & 10.4 & 0.188 & 12.2 \\
\hline L.K. & Bile fistula & 0.082 & 5.5 & 1.07 & 71.8 & 0.22 & 15.0 & 0.115 & 7.7 \\
\hline
\end{tabular}

* Phospholipid values are expressed as millimoles of phosphorus.

$\dagger$ The values for N.W. and I.H. not recorded because of inaccuracy due to small quantity of fraction. 
elevation of the ratio of free/total cholesterol in two and of the triglyceride concentration in all. The lysolecithin concentration was within the normal range. The sera of Patients H.S. and L.K. showed a faint opalescence, while the serum of F.M. was clear on inspection.

Serum lipoprotein fractions. In ten patients, aliquots of the same samples used for whole serum analysis were adjusted as to density, and fractions $\mathrm{D}<1.019,<1.063$ and $>1.063$ were separated by ultracentrifugation. The values for the lipid phosphorus in each density fraction are given in Table II. A striking elevation of the relative amount of lipid phosphorus in the fraction $\mathrm{D}<$ 1.063 is evident in the five patients with jaundice, even when the total serum lipid phosphorus was not elevated (I.H.). The absolute amount of lipid phosphorus was elevated in the fraction $D<1.063$ in all of the five and was lowered in the fraction $\mathrm{D}>1.063$ in three of the five. These changes were in contrast to the minimal, if any, deviations from normal observed in the patients with cirrhosis and with bile fistula. No consistent changes in the relative or absolute amount of total lipid phosphorus in the fraction $\mathrm{D}<1.019$ were seen. The fraction $\mathrm{D}>1.21$ was analyzed in Patients L.U. and L.K. and found to contain about 2 per cent and 4 per cent, respectively, of the total lipid phosphorus.

The values for the individual phospholipids in each density fraction are given in Tables III to V. The changes in the relative concentrations of the individual phospholipids as compared with the normal values were in the same direction as in whole serum. The sphingomyelin/lecithin ratio in the fraction $\mathrm{D}<1.063$ was considerably lower in the patients with jaundice than in those with cirrhosis and with bile fistula. This ratio, however, was considerably higher in the fraction $\mathrm{D}<1.063$ than in the fraction $\mathrm{D}>1.063$, as in normal subjects (25), suggesting that the relative binding affinities for these phospholipids by the respective lipoproteins were similar to the normal. The molar "cephalin"/sphingomyelin ratio was higher in the fraction $\mathrm{D}>1.063$ than in the fraction $\mathrm{D}<1.063$, as in normal subjects (25), suggesting that the relative binding affinities for these phospholipids by the respective lipoproteins were also similar to the normal. The "cephalin"/

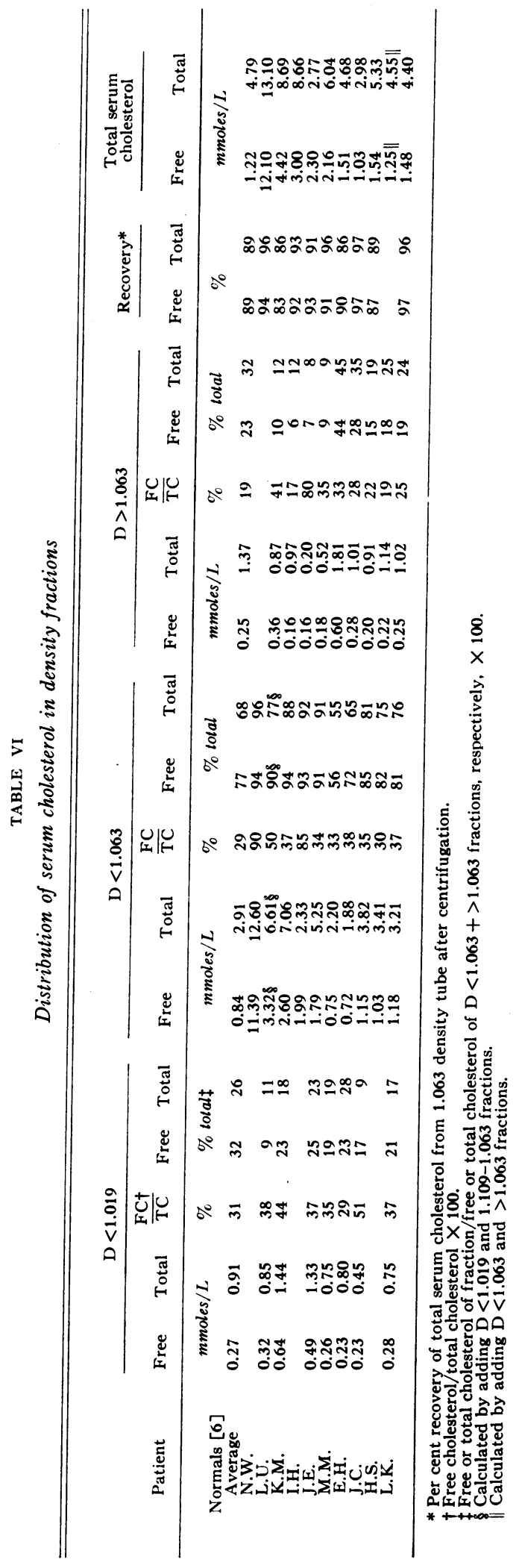


TABLE VII

Distribution of serum triglyceride in density fractions

\begin{tabular}{|c|c|c|c|c|c|c|c|c|}
\hline \multirow{3}{*}{\begin{tabular}{l}
\multicolumn{1}{c}{ Patient } \\
Normals [5] \\
Average \\
N.W.
\end{tabular}} & \multicolumn{2}{|c|}{$\mathrm{D}<1.019$} & \multicolumn{2}{|c|}{$\mathrm{D}<1.063$} & \multicolumn{2}{|c|}{$D>1.063$} & \multirow{2}{*}{$\frac{\text { Recovery* }}{\%}$} & \multirow{2}{*}{$\begin{array}{c}\begin{array}{c}\text { Total } \\
\text { serum } \\
\text { triglyceride }\end{array} \\
\text { mmoles } / L\end{array}$} \\
\hline & mmoles $/ L$ & $\%$ total & mmoles $/ L$ & $\%$ total & mmoles $/ L$ & $\%$ total & & \\
\hline & & & $\begin{array}{l}0.54 \\
1.55\end{array}$ & $\begin{array}{l}85 \\
94\end{array}$ & 0.10 & 15 & & $\begin{array}{l}0.64 \dagger \\
1.65\end{array}$ \\
\hline K.M. & 1.85 & 73 & 2.38 & 94 & 0.15 & 6 & 80 & 3.15 \\
\hline I.H. & & & 1.62 & 95 & 0.08 & 5 & 88 & 1.92 \\
\hline J.E. & 1.57 & 55 & 2.62 & 92 & 0.24 & 8 & 102 & 2.79 \\
\hline M.M. & 0.47 & 55 & 0.52 & 61 & 0.33 & 39 & 100 & 0.86 \\
\hline E.H. & 0.33 & 42 & 0.60 & 78 & 0.17 & 22 & 93 & 0.83 \\
\hline J.C. & 0.60 & 48 & 1.05 & 85 & 0.19 & 15 & 101 & 1.22 \\
\hline H.S. & & & 1.92 & 88 & 0.25 & 12 & & $2.17 \dagger$ \\
\hline L.K. & 1.11 & 67 & 1.42 & 86 & 0.23 & 14 & 90 & 1.84 \\
\hline
\end{tabular}

* Per cent recovery of total serum triglyceride from 1.063 density tube after centrifugation.

$\dagger$ Calculated by adding $D<1.063$ and $>1.063$ fractions.

lecithin ratios in both fractions were similar to the respective values found in normal subjects (25).

The distribution of free and total cholesterol in the density fractions of these ten patients is shown in Table VI. All of the patients with jaundice showed a relative elevation of free and total cholesterol as well as an absolute elevation of free cholesterol in the fraction $\mathrm{D}<1.063$. In two of the jaundiced patients (L.U., I.H.), there was also a marked increase in the ratio of free/total cholesterol in the fractions $\mathrm{D}<1.063$ and $>1.063$.

The distribution of the triglyceride in the density fractions of nine of the patients is shown in Table VII. Although the error involved in this determination may be considerable, the patients with jaundice had a relatively greater amount of triglyceride in the fraction $\mathrm{D}<1.063$ than had the normal subjects or the other patients.

\section{DISCUSSION}

The data presented indicate that the presence of jaundice, whether parenchymatous or obstructive in origin, was associated with changes in the serum lipids, including the individual phospholipids, cholesterol, cholesterol ester and triglyceride, and in the serum lipoproteins.

Of the 12 patients with jaundice, 8 showed an elevation in serum lecithin concentration; the 4 patients who did not, likewise showed no elevation in total serum phospholipid concentration, in 2 (P.K., I.H.) probably because of severe parenchymal damage (5) and in 2 (J.E., J.M.) because of mild disease. But the percentage of the total phospholipid analyzed as lecithin was elevated in 11 of the 12 patients. The serum sphingomyelin and "cephalin" concentrations were more variable, the former usually being normal and the latter elevated. The ratio of sphingomyelin/lecithin, however, was lowered in all of the jaundiced patients. Similar results were reported by Petersen $(8,9)$, who estimated the individual phospholipids by measuring phospholipid fragments after hydrolysis.

The serum lysolecithin concentration appeared to be inversely related to the direct serum bilirubin concentration and was low in all of the patients with marked primary liver disease, being lowest and almost absent in a patient with acute hepatic insufficiency of the chronic alcoholic (23) and coma. The isolation, identification, and quantitation of lysolecithin in human serum have been described previously $(21,22)$ and confirmed (30, 31). About one-half of the serum lysolecithin, furthermore, appears to be concentrated in a lipoprotein fraction $\mathrm{D}>1.21$ (32). A decrease in the serum lysolecithin concentration, therefore, might be reflected in a decrease in the amount of lysolecithin in the lipoprotein fraction $\mathrm{D}>1.21$. Havel, Eder and Bragdon (19) reported that in eight patients with hyperlipoproteinemia, the amount of phospholipid in the fraction $\mathrm{D}>1.21$ was within the normal range. Furman, Norcia, Fryer and Wamack (33), however, noted that in a patient with biliary cirrhosis and a high lipid phosphorus level, almost no ethanol-ether soluble phosphorus was found in the fraction $\mathrm{D}>1.21$.

The decrease in the serum lysolecithin concentration in the patients with jaundice could be the result of biliary retention, of abnormal liver func- 
tion, or of both. Borgström (34) has shown that the lecithin of bile is converted to lysolecithin in the gastrointestinal tract. The lysolecithin of serum, therefore, may represent that absorbed from the gastrointestinal tract during digestion, and the decreased serum lysolecithin concentration in the patients with jaundice might have been the result of a decreased excretion of bile into the gastrointestinal tract, even though lecithin might have been introduced into the gastrointestinal tract in the diet. If the retention of bile lecithin parallels the serum bilirubin concentration, then the inverse relation between serum lysolecithin concentration and serum bilirubin concentration suggested in Figure 1 would be expected. This explanation for the decrease in serum lysolecithin concentration in patients with jaundice, however, seems unlikely for several reasons. First, the two patients with the obstructive type of jaundice showed normal levels of serum lysolecithin; but their serum bilirubin levels were lower than most of the other patients. Second, two patients with marked cirrhosis, ascites and edema showed decreases in the serum lysolecithin concentration, even though the serum bilirubin concentration was only slightly elevated. Third, three patients with bile fistula, who were losing much if not all of their bile for at least eight days before the serum lipid analysis, showed normal concentrations of serum lysolecithin. It seems likely, therefore, that the liver controls the level of and, as is the case with the other major phospholipids $(35,36)$ probably synthesizes and breaks down the lysolecithin of serum. Lysolecithinases, in fact, have been found in rat and sheep liver $(37,38)$. If this is the case, it apparently takes less hepatic damage to lower the level of the serum lysolecithin than that of the other serum phospholipids. The suggestive correlation of the serum lysolecithin concentration with the direct serum bilirubin concentration thus may represent a correlation with the severity of the parenchymal liver disease, as evidenced by the level of the direct serum bilirubin. The decrease in serum lysolecithin concentration, therefore, appears to be a result of decreased liver function, although the possibility still exists that it is also related to biliary retention in some as yet unknown way.

The association of parenchymatous and obstructive jaundice with an increase in the serum concentration of free cholesterol and in the ratio of free/total cholesterol, as well as the apparent direct relationship between the degree of jaundice and these functions, has been noted before $(2-5$, 10-12). The lack of a comparable degree of elevation in patients with bile fistula suggests that a decrease of bile in the gastrointestinal tract was not responsible for these changes. The serum cholesterol ester concentration, like the serum lysolecithin concentration, appeared to be inversely related to the serum bilirubin concentration and was decreased in one patient with marked cirrhosis without jaundice. These data suggest that, in patients with parenchymatous or obstructive jaundice, the decrease in cholesterol ester concentration, like the decrease in serum lysolecithin concentration, may be the result of parenchymal damage, while the increase in free cholesterol concentration, like the increase in serum lecithin concentration, is a consequence of biliary retention. Nevertheless, the possibility exists that the decrease in the cholesterol ester and lysolecithin concentrations may also be related to biliary retention as, for example, by competition with free cholesterol and lecithin, respectively, for lipoprotein binding sites. The increase in the ratio of serum free/total cholesterol in patients with jaundice of both causes, however, is usually attributed to a failure in the cholesterol esterification process.

The serum triglyceride concentration was elevated in nine of the patients with jaundice. The values obtained, however, may be in considerable error as they were calculated as the difference between the concentrations of total serum nonphosphorus-containing lipid ester and serum cholesterol ester, and evidence indicates that cholesterol ester may not give a quantitative color yield with the lipid ester method used (39-41). Nevertheless, even if cholesterol ester gave no color yield with this method, the triglyceride values would be elevated in half of the patients with jaundice and in all of the patients with bile fistula. All of the sera in the jaundiced patients, except for one from a patient with very mild hepatitis, however, were clear on inspection, possibly because of insufficient elevation of the serum triglyceride concentration (42). Ahrens and Kunkel (10) also noted ir-creased neutral fat concentrations with clear sera in patients with primary biliary cirrhosis, and Albrink, Man and Peters (11) found the serum neutral fat to be almost invariably elevated in pa- 
tients with obstructive jaundice. The elevation in the three patients with bile fistula and the lack of elevation in the patients with marked cirrhosis without jaundice suggest that the increased serum triglyceride concentration might have been related to the decreased delivery of bile into the gastrointestinal tract.

Analysis of the lipoprotein fractions ${ }^{2}$ separated by ultracentrifugation in five of the patients with jaundice revealed an elevation of the amount of lipid phosphorus in the fraction $\mathrm{D}<1.063$ in all, even when the total serum lipid phosphorus was not elevated, and a decrease in the amount of lipid phosphorus in the fraction $D>1.063$ in three of the five patients. Similar findings have been reported by others (15-19). The minimal, if any, deviation from the normal in these fractions in the nonjaundiced patients with cirrhosis and with bile fistula suggests that these changes are related to bile retention. The mechanism of these changes, however, is obscure. The ratios of the individual phospholipids, cholesterol and cholesterol ester in the density fractions were changed in the same direction as in whole serum. The sphingomyelin/ lecithin ratio, moreover, was considerably higher and the "cephalin"/sphingomyelin ratio lower in the fraction $\mathrm{D}<1.063$ than in $\mathrm{D}>1.063$, as in normal subjects (25), suggesting that the relative binding affinities for these phospholipids by the respective lipoproteins were similar to the normal.

Although it is difficult to dissociate the effects of biliary retention and parenchymal damage, the evidence presented suggests that in patients with jaundice the hyperlipemia, characterized by an increase in the concentrations of lecithin and free cholesterol, is a consequence of the biliary retention. Although the mechanism of such a relationship is unknown, two explanations may be considered. It has been suggested that the hyperlipemia of obstructive jaundice is a consequence of the retention of cholate in the plasma with a resultant trapping of plasma lipids $(44-46)$. This explanation seems unlikely, however, because the amount of bile salt in the serum of patients with jaundice is much smaller than the amounts of leci-

2 The fractions $D<1.063$ and $>1.063$ migrate as $\beta$ and $\alpha$-globulin, respectively, on paper electrophoresis (19), while the fraction $\mathrm{D}<1.019$ migrates as $\alpha_{2}$ globulin on zone electrophoresis (43). thin and free cholesterol $(47,48)$ and apparently most of the bile salt is bound to albumin (49). In addition, the hyperlipemia appears to be rather selective, in that it is largely accounted for by lecithin and free cholesterol. The second explanation seems more reasonable. It is probably more than coincidental that the lipids which account for most of the hyperlipemia in patients with jaundice, i.e., lecithin and free cholesterol, are the same lipids that account for essentially all of the lipid of bile (50-52). Although the liver apparently synthesizes lecithin and free cholesterol, the hyperlipemia could result from an inability of the liver to excrete these lipids into the bile as a result of parenchymal damage or from a regurgitation of the bile lipids into the blood as a result of biliary obstruction. Evidence offered against this hypothesis has been the demonstration of an increased rate of synthesis of plasma cholesterol following bile duct ligation in the rat (53) and of an increased rate of plasma phospholipid synthesis in patients with jaundice and hyperlipemia (54). It is conceivable, however, that the increased rate of synthesis of these lipids may represent an increment in synthesis that ordinarily is excreted into the bile but in jaundiced patients finds its way into the plasma. Other explanations for the hyperlipemia, however, are possible, and selection of the correct one must await further studies.

\section{SUMMARY}

The serum lipids, including the individual phospholipids, free cholesterol, cholesterol ester, and triglyceride were analyzed in 12 patients with parenchymatous or obstructive jaundice, in 3 patients with cirrhosis without jaundice, and in 3 patients with bile fistula.

The serum lipids of the patients with parenchymatous or obstructive jaundice showed a characteristic pattern, even when the total serum lipid concentration was not elevated, which included 1) elevation of the lecithin concentration and, more consistently, of the ratio of lecithin/total phospholipid, 2) elevation of the free cholesterol concentration and of the ratio of free/total cholesterol, and 3) elevation of the concentration of the lipoprotein fraction with density (D) $<1.063$ and lowering of the concentration of the lipoprotein fraction $\mathrm{D}>1.063$, and more consistently, elevation of the ratio of the former to the latter. 
These serum lipid changes were not seen in the nonjaundiced patients with cirrhosis and with bile fistula, except for some elevation of the ratio of free/total cholesterol, suggesting that this pattern was a concomitant of bile retention rather than of parenchymal damage or decrease in the amount of bile delivered to the gastrointestinal tract.

The serum lipids of the lipoprotein fractions separated by ultracentrifugation reflected the changes seen in whole serum and comparison with the corresponding fractions of normal subjects suggested that the relative binding affinities of the lipoproteins for the individual phospholipids were similar to the normal in all of the patients.

The serum lysolecithin concentration in the patients with parenchymatous jaundice appeared to be inversely related to the direct serum bilirubin concentration. The lowered concentration of lysolecithin in two nonjaundiced patients with cirrhosis and the normal concentration in the three patients with bile fistula suggested that the lysolecithin concentration reflected parenchymal function and that the liver controls the level of and may be the source of this phospholipid.

The serum cholesterol ester concentration varied similarly to the serum lysolecithin concentration and likewise may be related to parenchymal function.

The serum triglyceride concentration was elevated in most of the jaundiced patients and in the patients with bile fistula.

It appears that parenchymal liver damage has a depressing effect upon the serum concentrations of the phospholipids, free cholesterol, and cholesterol ester, while biliary retention tends to elevate the serum concentrations of lecithin and free cholesterol.

\section{REFERENCES}

1. Flint, A., Jr. Experimental researches into a new excretory function of the liver; consisting in the removal of cholesterine from the blood, and its discharge from the body in the form of stercorine. Amer. J. med. Sci. 1862, 44, 305.

2. Feigl, J. Neue Untersuchungen ïber akute gelbe Leberatrophie. III. Fette und Lipoide des Blutes. Chemische Beiträge zur Kenntnis der Entwicklung und Charakteristik spezifischer Lipämien. Biochem. Z. 1918, 86, 1.

3. Thannhauser, S. J., and Schaber, H. Über die Beziehungen des Gleichgewichtes Cholesterin und Cholesterinester im Blut und Serum zur Leberfunktion. Klin. Wschr. 1926, 5, 252.
4. Epstein, E. Z. Cholesterol of the blood plasma in hepatic and biliary diseases. Arch. intern. Med. 1932, 50, 203.

5. Man, E. B., Kartin, B. L., Durlacher, S. H., and Peters, J. P. The lipids of serum and liver in patients with hepatic diseases. J. clin. Invest. 1945, 24, 623.

6. Thannhauser, S. J., and Magendantz, H. The different clinical groups of xanthomatous diseases; a clinical physiological study of 22 cases. Ann. intern. Med. 1938, 11, 1662.

7. Albrink, M. J. The choline-containing phospholipids of serum. J. clin. Invest. 1950, 29, 46.

8. Petersen, V. P. The individual plasma phospholipids in acute hepatitis. Acta med. scand. 1953, 144, 333.

9. Petersen, V. P. The individual plasma phospholipids in obstructive jaundice. Acta med. scand. 1953, 144, 345.

10. Ahrens, E. H., Jr., and Kunkel, H. G. The relationship between serum lipids and skin xanthomata in eighteen patients with primary biliary cirrhosis. J. clin. Invest. 1949, 28, 1565.

11. Albrink, M. J., Man, E. B., and Peters, J. P. Serum lipids in infectious hepatitis and obstructive jaundice. J. clin. Invest. 1950, 29, 781.

12. Zieve, L. Studies of liver function tests. III. Dependence of percentage cholesterol esters upon the degree of jaundice. J. Lab. clin. Med. 1953, 42, 134.

13. McGinley, J., Jones, H., and Gofman, J. Lipoproteins and xanthomatous diseases. J. invest. Derm. 1952, 19, 71.

14. Pierce, F. T., Jr., Kimmel, J. R., and Burns, T. W. Lipoproteins in infectious and serum hepatitis. Metabolism 1954, 3, 228.

15. Kunkel, H. G., and Slater, R. J. Lipoprotein patterns of serum obtained by zone electrophoresis. J. clin. Invest. 1952, 31, 677.

16. Nikkilä, E. Studies on the lipid-protein relationships in normal and pathological sera and the effect of heparin on serum lipoproteins. Scand. J. clin. Lab. Invest. 1953, 5, suppl. 8.

17. Eder, H. A., Russ, E. M., Pritchett, R. A. R., Wilber, M. M., and Barr, D. P. Protein-lipid relationships in human plasma: In biliary cirrhosis, obstructive jaundice, and acute hepatitis. J. clin. Invest. 1955, 34, 1147.

18. Furman, R. H., Conrad, L. L., and Howard, R. P. A serum lipoprotein pattern characteristic of biliary obstruction, with some comments on "jaundice due to methyltestosterone" (abstract). Circulation 1954, 10, 586.

19. Havel, R. J., Eder, H. A., and Bragdon, J. H. The distribution and chemical composition of ultracentrifugally separated lipoproteins in human serum. J. clin. Invest. 1955, 34, 1345.

20. Russ, E. M., Raymunt, J., and Barr, D. P. Lipoproteins in primary biliary cirrhosis. J. clin. Invest. $1956,35,133$. 
21. Phillips, G. B. The isolation of lysolecithin from human serum. Proc. nat. Acad. Sci. (Wash.) 1957, 43, 566.

22. Phillips, G. B. The isolation and quantitation of the principal phospholipid components of human serum using chromatography on silicic acid. Biochim. biophys. Acta 1958, 29, 594.

23. Phillips, G. B., and Davidson, C. S. Acute hepatic insufficiency of the chronic alcoholic. Clinical and pathological study. Arch. intern. Med. 1954, 94, 585.

24. Malloy, H. T., and Evelyn, K. A. The determination of bilirubin with the photoelectric colorimeter. J. biol. Chem. 1937, 119, 481.

25. Phillips, G. B. The phospholipid composition of human serum lipoprotein fractions separated by ultracentrifugation. J. clin. Invest. 1959, 38, 489.

26. Fiske, C. H., and Subbarow, Y. The colorimetric determination of phosphorus. J. biol. Chem. 1925, $66,375$.

27. Schoenheimer, R., and Sperry, W. M. A micromethod for the determination of free and combined cholesterol. J. biol. Chem. 1934, 106, 745.

28. Sperry, W. M., and Webb, M. A revision of the Schoenheimer-Sperry method for cholesterol determination. J. biol. Chem. 1950, 187, 97.

29. Rapport, M. M., and Alonzo, N. Photometric determination of fatty acid ester groups in phospholipides. J. biol. Chem. 1955, 217, 193.

30. Gjone, E., Berry, J. F., and Turner, D. A. Isolation and identification of lysolecithin from lipid extracts of normal human serum. Biochim. biophys. Acta 1959, 34, 288.

31. Marinetti, G. V., Albrecht, M., Ford, T., and Stotz, E. Analysis of human plasma phosphatides by paper chromatography. Biochim. biophys. Acta 1959, 36, 4.

32. Phillips, G. B. Lipid composition of human serum lipoprotein fraction with density greater than 1.210 . Proc. Soc. exp. Biol. (N. Y.) 1959, 100, 19.

33. Furman, R. H., Norcia, L. N., Fryer, A. W., and Wamack, B. S. Lipoprotein recovery following ultracentrifugal fractionation at solvent density 1.21 as determined by cholesterol and lipid phosphorus analyses of supernatant and bottom fractions. J. Lab. clin. Med. 1956, 47, 730.

34. Borgström, B. Studies of the phospholipids of human hile and small intestinal content. Acta chem. scand. 1957, 11, 749.

35. Fishler, M. C., Entenman, C., Montgomery, M. L., and Chaikoff, I. L. The formation of phospholipid by the hepatectomized dog as measured with radioactive phosphorus. I. The site of formation of plasma phospholipids. J. biol. Chem. 1943, 150, 47.

36. Entenman, C., Chaikoff, I. L., and Zilversmit, D. B. Removal of plasma phospholipides as a function of the liver: The effect of exclusion of the liver on the turnover rate of plasma phospholipides as measured with radioactive phosphorus. J. biol. Chem. 1946, 166, 15.
37. Dawson, R. M. C. The phospholipase B of liver. Biochem. J. 1956, 64, 192.

38. Marinetti, G. V., Erbland, J., Witter, R. F., Petix, J., and Stotz, E. Metabolic pathways of lysolecithin in a soluble rat-liver system. Biochim. biophys. Acta 1958, 30, 223.

39. Entenman, C. Preparation and determination of higher fatty acids in Methods in Enzymology, S. P. Colowick and N. O. Kaplan, Eds. New York, Academic Press, 1957, vol. 3, p. 323.

40. Kuo, P. T., and Carson, J. C. Dietary fats and the diurnal serum triglyceride levels in man. J. clin. Invest. 1959, 38, 1384.

41. Hack, M. H. A method for the estimation of fatty acid esters. Arch. Biochem. 1955, 58, 19.

42. Albrink, M. J., Man, E. B., and Peters, J. P. The relation of neutral fat to lactescence of serum. J. clin. Invest. 1955, 34, 147.

43. Kunkel, H. G., and Trautman, R. The $\alpha_{2}$ lipoproteins of human serum. Correlation of ultracentrifugal and electrophoretic properties. J. clin. Invest. $1956,35,641$.

44. Friedman, M., and Byers, S. O. Cholic acid: An adequate stimulus for hypercholesteremia in the normal fasting rat. Proc. Soc. exp. Biol. (N. Y.) 1951, 78, 528.

45. Friedman, M., Byers, S. O., and Rosenman, R. H. The accumulation of serum cholate and its rela. tionship to hypercholesteremia. Science 1952, 115, 313.

46. Byers, S. O., Friedman, M., Biggs, M. W., and Gunning, B. Observations concerning the production and excretion of cholesterol in mammals. IX. The mechanism of the hypercholesteremic effect of cholic acid. J. exp. Med. 1953, 97, 511.

47. Rudman, D., and Kendall, F. E. Bile acid content of human serum. I. Serum bile acids in patients with hepatic disease. J. clin. Invest. 1957, 36, 530.

48. Carey, J. B., Jr. The serum trihydroxy-dihydroxy bile acid ratio in liver and biliary tract disease. J. clin. Invest. 1958, 37, 1494.

49. Rudman, D., and Kendall, F. E. Bile acid content of human serum. II. The binding of cholanic acids by human plasma proteins. J. clin. Invest. 1957, 36, 538.

50. Polonovski, M., and Bourrillon, R. Les phospholipides de la bile. Bull. Soc. Chim. biol. (Paris) 1952, 34, 712.

51. Isaksson, B. On the lipid constituents of normal bile. Acta Soc. Med. upsalien. 1952, 56, 177.

52. Phillips, G. B. The lipid composition of human bile. Biochim. biophys. Acta 1960, 41, 361.

53. Frederickson, D. S., Loud, A. V., Hinkelman, B. T., Schneider, H. S., and Frantz, I. D., Jr. The effect of ligation of the common bile duct on cholesterol synthesis in the rat. J. exp. Med. 1954, 99, 43.

54. Balfour, W. M. Human plasma phospholipid formation: A study made with the aid of radiophosphorus. Gastroenterology 1947, 9, 686. 